\title{
Oil droplets turn cells into tiny lasers
}

Injecting single cells with spheres of fluorescent dye could open new research and treatment avenues using light.

\section{Allie Wilkinson}

27 July 2015

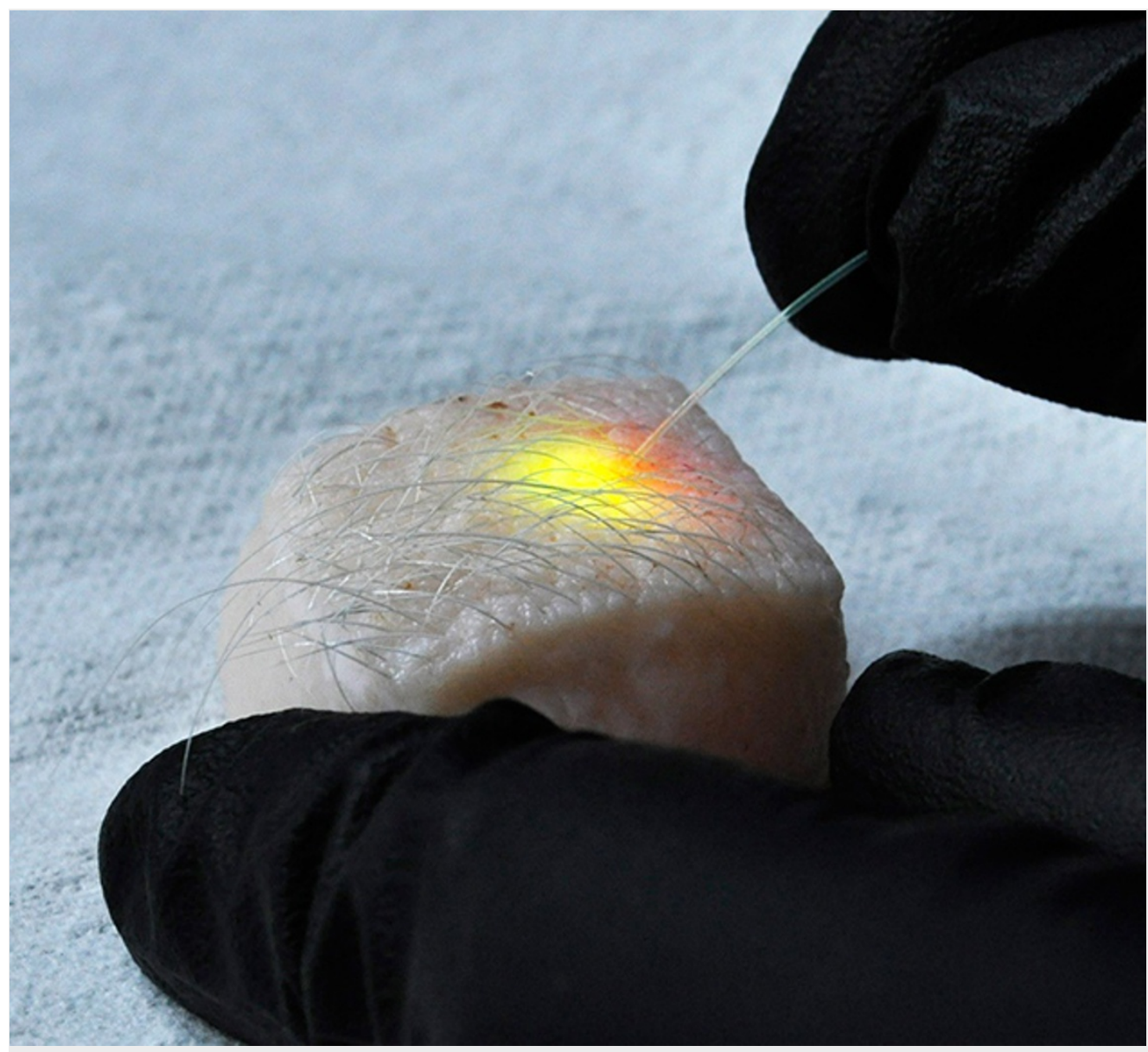

Matjaž Humar/Seok Hyun Yun

An optical fibre is shown activating tiny lasers created within pig skin cells.

Scientists have turned individual cells into miniature lasers by injecting them with droplets of oil or fat mixed with a fluorescent dye that can be activated by short pulses of light.

The finding, reported on 27 July in Nature Photonics ${ }^{1}$, could help to broaden how light is used for both medical diagnosis and treatment.

The system was devised by Seok Hyun Yun and Matjaž Humar, both optical physicists at Harvard Medical School in Cambridge, Massachusetts, and uses droplets of fat or oil within a cell to reflect and amplify light, generating a laser.

Yun had previously reported a method for generating laser light by engineering cells to express a fluorescent jellyfish protein, then placing a single such cell between a pair of external mirrors ${ }^{2}$. His latest work goes a step further, producing a cell with a self-contained laser.

Conventional luminescent probes, which include fluorescent dyes and proteins, have relatively broad emission spectra. This limits the number of probes that can be used simultaneously, because it is often difficult to distinguish these sources of luminescence from the broad background emissions of naturally occurring molecules in tissue. 


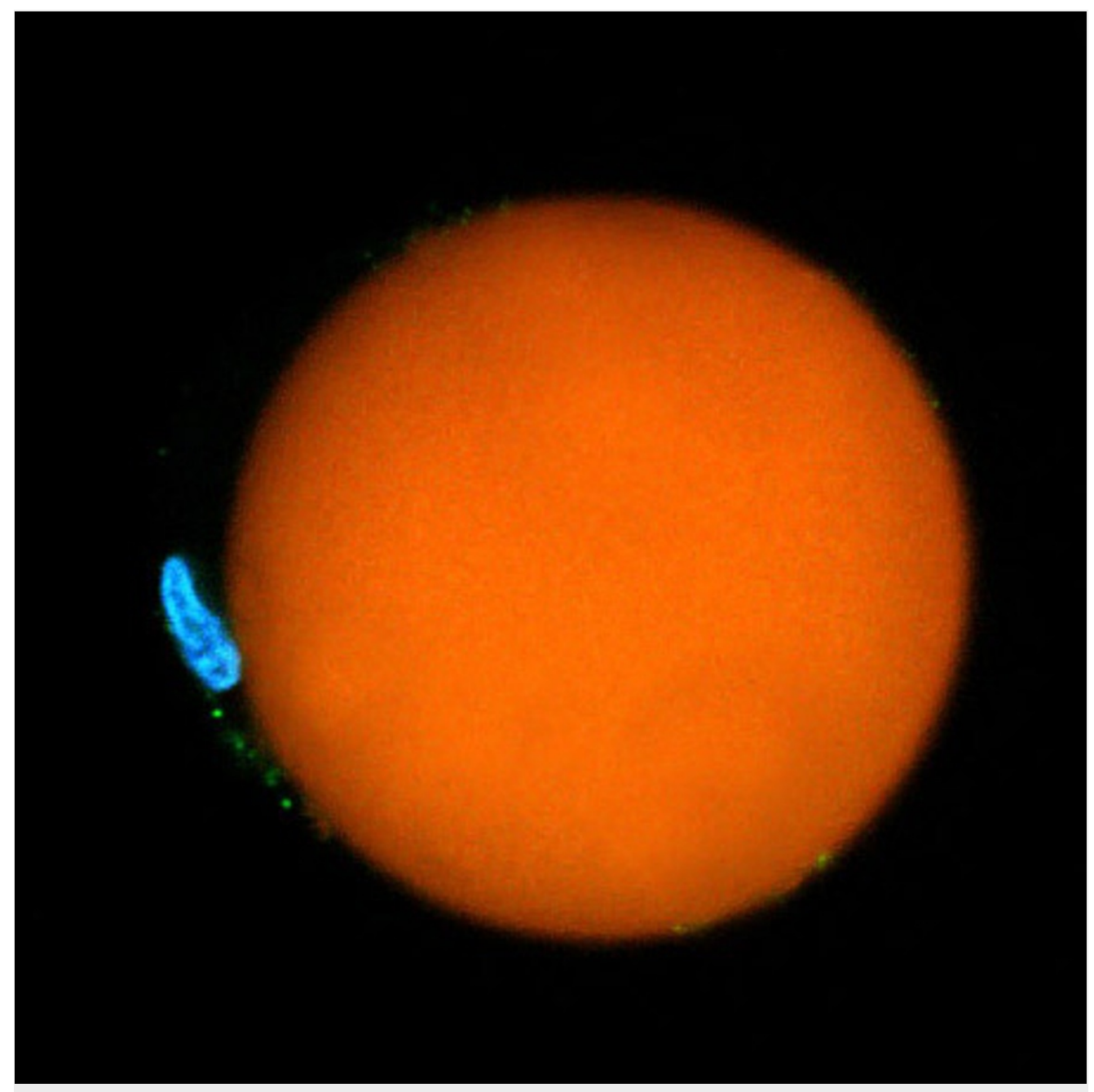

Matjaž Humar/Seok Hyun Yun

The lipid droplet (orange) within a fat cell can be used as a natural laser.

The microlasers could change this because their emission spectrum is narrow, making it easier to label cells with light, says Jeffrey Karp, a bioengineer at Brigham and Women's Hospital in Boston, Massachusetts. "One of the greatest implications of the work is to track thousands of cells simultaneously with a single technique," he says.

Yun and Humar report that they can vary the wavelength and tag individual cells using fluorescent polystyrene beads of different diameters, rather than injected droplets of oil or fat. In theory, using different combinations of beads and dyes with different spectral properties should make it possible to individually tag almost as many cells as exist in the human body.

"It will be fun or very exciting to adapt the knowledge that's in the traditional laser community and explore that in this platform to optimize laser characteristics," says Yun.

He cautions that the technique is not yet ready for therapeutic use. But eventually the modified cells could be used to locate target tissue, such as a cancerous tumour, and active pre-loaded, light-sensitive drugs only in that area.

Nature | doi:10.1038/nature.2015.18061

\section{References}

1. Humar, M. \& Yun, S. H. Nature Photonics http://dx.doi.org/10.1038/nphoton.2015.129 (2015).

2. Gather, M. C. \& Yun, S. H. Nature Photonics 5, 406-410 (2011). 